\title{
Mobilização, conflitos e reconhecimento do território: comunidades quilombolas na Ilha do Marajó, Brasil
}

Mobilization, Conflicts and Recognition of the Territory: Quilombolas

Communities in the Marajó Island, Brazil

Mobilisation, conflits et reconnaissance du territoire: communautés quilombolas dans l'île do Marajó, Brésil

Pierre Teisserenc e Maria José da Silva Aquino Teisserenc

\section{OpenEdition}

\section{Journals}

Edição electrónica

URL: http://journals.openedition.org/rccs/6968

DOI: $10.4000 /$ rccs. 6968

ISSN: 2182-7435

\section{Editora}

Centro de Estudos Sociais da Universidade de Coimbra

Edição impressa

Data de publição: 1 Maio 2018

Paginação: 51-74

ISSN: 0254-1106

Refêrencia eletrónica

Pierre Teisserenc e Maria José da Silva Aquino Teisserenc, « Mobilização, conflitos e reconhecimento do território: comunidades quilombolas na Ilha do Marajó, Brasil », Revista Crítica de Ciências Sociais [Online], 115 | 2018, colocado online no dia 15 maio 2018, criado a 21 abril 2019. URL : http:// journals.openedition.org/rccs/6968; DOI : 10.4000/rccs.6968 


\section{PIERRE TEISSERENC, MARIA JOSÉ DA SILVA AQUINO TEISSERENC}

\section{Mobilização, conflitos e reconhecimento do território: comunidades quilombolas na Ilha do Marajó, Brasil*}

Neste artigo discute-se a implementação de um dispositivo da Constituição Brasileira de 1988 para reparar a situação de injustiça histórica vivida pelas comunidades quilombolas de Salvaterra, Ilha de Marajó, enquanto oportunidade de uma mobilização de caráter identitário para reivindicar o reconhecimento de direitos sociais. Como o poder local não se compromete com essa implementação, mas ao mesmo tempo é interpelado quanto a tomar medidas concretas no território, resultam então tensões e conflitos manifestos nas esferas política e religiosa. As estratégias dos Quilombolas face às autoridades locais, religiosas e políticas, visando reconhecimento diferenciado, contribuem para uma politização dos desafios locais, embora o dispositivo constitucional acionado não ofereça meios para que a mobilização ponha em causa um sistema de dominação tradicional no qual se assenta o poder local.

Palavras-chaves: comunidades quilombolas; identidade; mobilização; politização; sociologia dos conflitos; territorialidade.

\footnotetext{
* Tratamos a questão da mobilização em relação a um contexto de reconhecimento do território, mais do que de reconhecimento identitário. Uma das características das comunidades quilombolas, tratada neste artigo um pouco mais à frente, é compreender o seu território como um espaço de vida e de afirmação de identidade e cultura que informa uma diversidade de práticas às quais esta identidade se refere. No sentido enunciado por Edna Castro: "Esses grupos experimentam um movimento que pretende recuperar a identidade outrora de seu grupo, via construção identitária através de processos políticos de afirmação sobre o território [...]. A reivindicação maior é o reconhecimento e demarcação de suas terras" (Castro, 1997: 236-237). Como também enunciado no "Manifesto pelos direitos quilombolas", elaborado pela Coordenação Nacional de Articulação das Comunidades Negras Rurais Quilombolas - CONAQ: "Nesse sentido, entendemos que a noção dos territórios das comunidades quilombolas com vistas a garantir a reprodução física, social e cultural do grupo, deve levar em consideração as áreas utilizadas para moradia, atividade econômica, caminhos e percursos, uso dos recursos naturais, realização dos cultos religiosos e festividades, bem como outras manifestações culturais e manifestações de caráter cosmológico" (CONAQ, 2010: 287).
} 
O presente artigo trata da maneira pela qual as 16 comunidades quilombolas $^{1}$ do município de Salvaterra, na Ilha do Marajó, ${ }^{2}$ estado do Pará, no Brasil, conseguiram se mobilizar como Quilombolas para fazerem valer os direitos que, reconhecidos pela Constituição Brasileira de $1988,{ }^{3}$ concernem em particular ao direito ao uso da terra e ao reconhecimento de sua cultura. Nos concentraremos particularmente nas razões pelas quais essa mobilização, organizada para responder às exigências jurídicas da Constituição, não se limita à reivindicação de seus novos direitos, mas se baseia, ao mesmo tempo, na afirmação identitária, sendo acompanhada por engajamentos de caráter político a nível local (Teisserenc, 2016b).

Nossa reflexão partiu da constatação do que há de paradoxal no fato de essas comunidades conseguirem se organizar de modo relativamente consensual para defender os seus novos direitos e os interesses ligados a eles e, ao mesmo tempo, de os membros dessas comunidades encontrarem muitas dificuldades em constituir uma frente comum e em desenvolver as suas estratégias coletivas para se apresentarem como sujeito político e, assim, exercerem influência sobre o poder local. Decidimos privilegiar como fio condutor de nossa análise a existência dessa assimetria entre a mobilização social e o engajamento político, de modo a descrever os mecanismos dessa mobilização social e a apreciar melhor as incertezas políticas encontradas por essa mobilização.

Para compreender a situação dessas comunidades, lembremos que os novos direitos reconhecidos pela Constituição aos Quilombolas, em especial o uso comum da terra, privilegiam um tratamento comunitário da situação por meio da possibilidade de livre escolha por parte de cada um dos membros de uma comunidade no que toca a reconhecer-se como quilombola, a partir do princípio de autodefinição. O tratamento comunitário que, em seguida, é engajado baseia-se nas relações contratuais (Almeida et al., 2010: 335)

\footnotetext{
${ }^{1}$ Consideramos a situação dos Quilombolas neste artigo, conforme descrito por Alfredo Wagner de Almeida (2002) e retomada por Eduardo Marques e Lilian Gomes (2013: 141), como "um fenômeno sociológico que se caracteriza por: (1) identidade e território indissociáveis; (2) processos sociais e políticos específicos que permitiram aos grupos uma autonomia; e (3) territorialidade específica, cortada pelo vetor étnico no qual grupos sociais específicos buscam ser reconhecidos. Portanto, corresponde a uma afirmação a um só tempo étnica e política".

${ }^{2}$ Estudo realizado pelos autores no período de 2012 a 2016 no âmbito do projeto de pesquisa "Desafios do reconhecimento a comunidades quilombolas: atores, relações e conflitos na Ilha de Marajó (PA)". O projeto, financiado pelo CNPq, foi coordenado por Luís Fernando Cardoso e Cardoso, antropólogo e professor da Universidade Federal do Pará, a quem muito agradecemos pelo aprendizado, convivívio e oportunidade de colaboração acadêmica.

${ }^{3}$ Em referência ao art. 68 do Ato das Disposições Constitucionais Provisórias (ADCT) dessa Constituição (Brasil, 1988), que considera essas comunidades como "bens do patrimônio brasileiro [...] a serem protegidos".
} 
que essas comunidades são convidadas a negociar com o Instituto Nacional de Colonização e Reforma Agrária (INCRA), enquanto instituição pública do Governo Federal, com o apoio da Fundação Cultural Palmares e dos cientistas habilitados a reconhecê-las enquanto autênticas.

Para uma compreensão mais adequada das hipóteses que organizam a apresentação dos resultados de nossas pesquisas, faz-se necessário três observações preliminares, a seguir apresentadas, relativas ao contexto jurídico e institucional estabelecido para regulamentar esse assunto.

\section{A emergência do ator "quilombola" na cena pública}

A primeira dessas observações concerne às consequências da decisão tomada pelos poderes públicos brasileiros em utilizar a categoria "quilombola" para propor uma resposta jurídica à sua situação. Essa categoria, ambígua na medida em que se aplica a situações heterogêneas, como já demonstrado (Marques e Gomes, 2013: 144-145; Almeida et al., 2010; Léna, 2002), quando se consideram os debates ${ }^{4}$ envolvendo cientistas sociais e representantes da administração pública, ${ }^{5}$ remetem habitualmente a uma realidade muito mais política do que sociológica. De fato, em um contexto fortemente marcado pelos debates sobre o reconhecimento do Brasil como uma nação pluricultural (Santilli, 2005; Gomes, 2009), e pela importância alcançada pelos movimentos de reivindicação fundiária dos anos de 1980, a resposta dada aos remanescentes de quilombos, chamados "quilombolas", se baseia na ideia das comunidades em sua diversidade, compartilhando "uma concepção da terra de uso comum, acionada como elemento de identidade indissociável do território ocupado e das regras de apropriação" (Almeida, 2008b: 113). A escolha da palavra "quilombola" segundo ainda Philippe Léna (2002), evidencia a vontade das autoridades públicas brasileiras de instituir uma categoria operacional no campo das políticas públicas

\footnotetext{
${ }^{4}$ Esses debates se deram especialmente sobre a questão de uma noção identificada com uma imagem negativa dos escravos fugitivos e a necessidade de propor uma definição "positiva" dos Quilombolas e de sua identidade como uma realidade em construção, "como a possibilidade de ser" (Almeida, 1996: 17).

5 Para compreender o que está em jogo, lembremos que o termo "quilombo" se impõe ainda durante a fase colonial e que durante todo o período imperial da história do Brasil permanece como uma categoria vinculada à criminalidade, à marginalidade e ao banditismo. Hoje é considerado, de acordo com a perspectiva antropológica, como um ente vivo e dinâmico, "um locus de produção simbólica, sujeito a mudanças culturais" (Marques e Gomes, 2013: 143). Na sequência da abolição dos escravos em 1889, a Constituição da jovem República brasileira nada menciona sobre a situação dos ex-escravos. Quase um século depois é que uma nova Constituição, ainda vigente, integra o conceito de "remanescente de quilombo", assim passando a ser considerada no plano jurídico uma situação de injustiça social que ficara sem solução desde o fim da escravidão e da proclamação da República.
} 
para facilitar o tratamento dos problemas que esta categorização tem por objetivo identificar.

A segunda observação volta-se para a distorção resultante da distância entre o contexto local, no qual acontece a mobilização dessas comunidades em defesa de seus direitos, e o quadro geral proposto pela Constituição. Neste quadro prevê-se atribuir o essencial das competências para a aplicação destes direitos, em termos de tratamento dos problemas, ao INCRA, agência do Governo Federal, e aos seus parceiros. Ao poder local é deixada a responsabilidade pelo tratamento dos efeitos territoriais da aplicação dos direitos. O resultado é que, no plano local, as comunidades quilombolas podem aspirar apenas a algumas vantagens diferenciadas, ${ }^{6}$ embora o reconhecimento do território e da identidade quilombolas pelo Estado produza efeitos territoriais importantes sem que localmente exista um espaço público para tratá-los, fora do contexto de eleições municipais. Nas modalidades de solucionamento da situação dos quilombolas, essa distorção permitiria explicar porque a problemática local de um engajamento político coletivo para pressionar o poder local perde a sua pertinência, na medida em que as vantagens específicas às quais eles poderiam aspirar, e que eles poderiam defender localmente, são relativamente limitadas e uma vez que, nesse contexto, prevalecem engajamentos políticos individuais que correspondem aos engajamentos de cidadãos ordinários.

A terceira observação concerne ao fato de que, a partir do momento em que existem alguns interesses diferenciados a defender coletivamente ao nível local, as relações entre as comunidades e o poder local permanecem tributárias de um sistema de poder autoritário herdado do período colonial, presente no contexto do Ciclo da borracha, com base no sistema de aviamento, cujas características ainda hoje podem ser verificadas (Teisserenc, 2016a). A permanência de um tal sistema contribuiria para explicar os comportamentos individuais de dependência que se podem verificar em todos os domínios da vida cotidiana das populações e nas estratégias resultantes, testemunhando uma interiorização dessa dominação que, por sua vez, pode

\footnotetext{
${ }^{6}$ Os Quilombolas, como outros segmentos sociais, são beneficiários de um conjunto de políticas sociais públicas, tais como Bolsa Família, redução da tarifa de energia, Programa Minha Casa Minha Vida, Programa da agricultura familiar (Pronaf), isenção de pagamento de inscrição para concursos públicos, Bolsa Verde, implementação da educação quilombola na escola, etc. No entanto, o que é reconhecido pela Constituição é "uma minoria étnica, culturalmente diferenciada" (Santilli, 2005: 85), que as comunidades são estimuladas a afirmar. Em Salvaterra, até o momento, as comunidades quilombolas tiveram acesso ao programa habitacional "Minha Casa Minha Vida" e, com o apoio da prefeitura, foi iniciada a "educação quilombola" nas escolas situadas nas comunidades, abrangendo a realização de jogos olímpicos quilombolas e a valorização de um patrimônio cultural de dança, música e festejos.
} 
ser interpretada em termos de habitus (por referência a Pierre Bourdieu). Aqueles comportamentos afetariam a dinâmica da mobilização coletiva das comunidades pela defesa de seus novos direitos e afetariam ainda mais o engajamento político de seus membros.

No presente artigo, nos dedicaremos a explicar porque, no contexto de Salvaterra, a autodefinição por meio de uma categoria social não homogênea, que é vivida pelos membros das comunidades quilombolas como um ato de reconhecimento de sua identidade a título individual, está na origem de uma mobilização que, mesmo correndo riscos (a serem analisados), não se limita a satisfazer as exigências legais requeridas para a defesa de seus novos direitos. Ela é enriquecida, ao mesmo tempo, por uma expressão identitária coletiva, origem de novos conflitos (em particular no campo religioso e no campo político) e que resulta no fortalecimeno dessa mobilização.

Para tratar dessa problemática, escolhemos como quadro de análise a sociologia da ação coletiva aplicada a um contexto territorial, já que a mobilização em questão se desenvolve a partir de um território em torno da resolução de um problema - a situação de injustiça social das comunidades quilombolas -, cuja solução proposta remete a um modo de tratamento complexo, que se aproxima de uma ação pública territorial. Assim, à complexidade do problema tratado é adicionada a complexidade do dispositivo, considerando a situação dos Quilombolas como um problema de política pública, cujo tratamento compete ao Estado federal, cabendo ao poder local cuidar de seus efeitos territoriais. ${ }^{7}$ É essa dupla complexidade (a do problema tratado e do dispositivo escolhido pelas autoridades públicas) que nos conduziu, para dar conta da mobilização das comunidades quilombolas, a privilegiar duas abordagens sociológicas da ação coletiva, que partilham o fato de conceder um lugar central à estratégia dos atores: a abordagem de Mancur Olson e a de Daniel Cefaï.

A primeira se baseia numa concepção de engajamento que faz referência a um ator racional em sua capacidade de cálculo e de escolha, e visa demonstrar como tal engajamento, que geralmente coloca em questão a satisfação de interesses comuns, é justificado pelos mecanismos de redistribuição que permitem a cada um esperar os benefícios individuais da produção da ação coletiva.

A segunda privilegia as situações locais que estão na origem de arenas públicas cuja produção de ação coletiva de caráter público se baseia no

\footnotetext{
7 A "Carta Compromisso", elaborada coletivamente em 2012 pelos Quilombolas durante a campanha eleitoral, composta de um exaustivo conjunto de reivindicações apresentado aos candidatos a Prefeito, objetivando apoiar coletivamente a candidatura disposta a atendê-las. Essa Carta, da qual uma cópia nos foi cedida, dá-nos uma ideia precisa das expectativas das comunidades e testemunha a vontade de reclamar direitos diferenciados em todos os domínios da vida cotidiana.
} 
engajamento de atores e no estado de sua opinião. Nesse contexto, a mobilização procede por etapas, mobilizando, num primeiro momento, recursos de todos os tipos, como os recursos organizacionais, as relações de parentesco e de comunidade, atos solidários e as expressões culturais e identitárias. Com isso, num segundo momento, os atores engajam-se na identificação dos problemas e projetos comuns. No terceiro momento acorda-se em torno de uma ideia do bem comum para assim facilitar a passagem para a ação coletiva.

No caso em análise, o dispositivo proposto pela Constituição se apresenta como uma arena pública, no sentido de Daniel Cefaï, à qual cada membro das comunidades acede pelo ato de autodefinição. Uma arena no interior da qual intervêm sucessivamente as comunidades, os especialistas encarregados de tratar os diferentes aspectos do problema, os agentes do INCRA e seus parceiros (a Fundação Palmares e os cientistas habilitados na identificação das comunidades e seus membros). É claro que, no interior do jogo de vantagens esperadas, as possibilidades de redistribuição individual são muito limitadas, pois se trata, para todos os membros das comunidades quilombolas, de obter um direito de uso coletivo da terra que proíbe qualquer forma de apropriação individual (Almeida et al., 2010: 328-333). Por outro lado, o trabalho coletivo engajado no interior das comunidades e entre elas é a ocasião de manifestações e de reivindicações que vão além do que foi previsto pelo quadro legal e que contribuem para a sua mobilização. ${ }^{8}$

Assim, nós gostaríamos de tirar proveito da análise desse caso para discutir e completar a teoria de Mancur Olson (1999), mostrando que, mesmo se o benefício buscado por cada um dos membros das comunidades é comum (a propriedade do uso coletivo da terra), ${ }^{9}$ o reconhecimento identitário que acompanha esse direito à terra é, para cada membro, um benefício individual. Esse último contribui para a mobilização dos membros para além da resolução do problema fundiário e apesar das divergências e dissidências que se desenvolvem no interior das comunidades na ocasião da resolução desse problema. A manutenção dessa mobilização se alimenta das trocas entre os membros das comunidades e o conjunto dos seus parceiros

\footnotetext{
8 "Verifica-se também um intenso processo de mobilização quilombola gravitando [...] em torno de direitos territoriais ou de livre acesso a recursos florestais, hídricos e do solo para fins de moradia e cultivo" (Almeida et al., 2010: 333).

9 Para os Quilombolas de Salvaterra, a reivindicação do direito à terra e o reconhecimento de seu território são os primeiros itens da lista de reivindicações inscritas na Carta Compromisso, já referida. Uma prioridade confirmada por Edna Castro: "a reinvindicaçao maior é o reconhecimento e a demarcação de suas terras. Campo de lutas no qual se movimentam como ações de duplo sentido: afirmação identitária e reconhecimento legal das terras herdadas dos ancestrais" (Castro, 2000: 178).
} 
(os representantes do Estado federal, os especialistas e técnicos de todas as partes, etc.), desenvolvidas no interior dessa arena pública e de engajamentos comunitários de natureza identitária, que permitem que os membros das comunidades realizem a passagem para a ação coletiva.

Essa interpretação se justifica pelo fato de que o ato individual de autodefinição é, segundo Horácio Sant'Ana Júnior e Ana Caroline Miranda, acompanhado por aquilo que descrevem como

um processo coletivo de auto-constituição que se faz em meio a lutas e conquistas, tanto para a afirmação de sua identidade quanto para acessarem o controle sobre seus territórios, ressaltando que esse processo passa pelo estabelecimento de regras de conservação, bem como pela formação de alianças com agentes externos. (2013: 111)

Esse processo coletivo se alimenta das "raízes locais profundas e de laços de solidariedade" (Almeida, 2008a: 70), cujo efeito é despertar e reatualizar a mobilização. Segundo Alfredo Wagner de Almeida, o referido processo coletivo se explica pela existência de "um potencial de mobilização" representado pelas expectativas das comunidades quilombolas (Almeida, 2008b: 149).

Para chegar à nossa finalidade propomos, num primeiro momento, descrever as resistências de todos os tipos encontradas pelos membros das comunidades quilombolas para passar ao ato de autodefinição e os efeitos resultantes dessa passagem ao ato em termos de afirmação de suas culturas. Mostraremos, em particular, como o processo de autoconstituição permitido pelo ato de autodefinição se apóia, como sugerem Horácio Sant'Ana e Ana Caroline Pires Miranda, numa capacidade de organização interna e numa pesquisa de novas alianças com atores externos à comunidade, em particular da parte do movimento social e dos centros de recursos técnicos e científicos. Num segundo momento, nos interessaremos pelos riscos da mobilização e, em particular, pela influência exercida pelas Igrejas sobre os engajamentos individuais e coletivos dos membros das comunidades, insistindo em revelar o papel específico da questão religiosa nessa mobilização e as interferências que a mesma desempenha sobre a questão política. Isso nos permitirá, em considerações finais, esboçar algumas condições para a passagem de uma mobilização social para a mobilização de natureza mais política.

\section{As questões da autodefinição pelos Quilombolas de Salvaterra e pelas suas comunidades}

As quinze comunidades quilombolas situadas em Salvaterra possuem importância desigual. Elas representam por volta de 2700 habitantes, em um 
município cuja população total é pouco mais de 20000 (IBGE, 2010). Os membros dessas comunidades vivem da agricultura familiar, da pesca nos rios e do extrativismo nas florestas e/ou nas zonas de mangues. A localização dessas comunidades no coração da zona rural da região explica porque seus territórios estão imbricados nos espaços reservados às grandes fazendas que ocupam a parte essencial das zonas rurais do território das comunidades. As sobreposições que essa grande proximidade permite estão na origem de relações conflituais que, às vezes, são acompanhadas de acordos tácitos e negociados caso a caso entre os fazendeiros e os membros das comunidades; isso cria um clima permanente de tensões e de medo num contexto geral de conflitos.

Caso se queira compreender o que representa o ato de autodefinição pelos Quilombolas, é essencial se referir à sua origem comum e à maneira pela qual as comunidades se constituíram a partir da história de cada um dos seus membros. O que nós reteremos dessa história é que os Quilombolas partilham o fato de serem descendentes de um escravo ancestral que traiu o seu mestre e conseguiu fugir da "Casa Grande". Esse ato de traição resultou de uma estratégia individual realizada com o objetivo exclusivo de romper com o sistema escravocrata e acessar uma vida mais livre, escondendo-se para não ser denunciado e executado. A organização desses antigos escravos em comunidades de fugitivos repousou na transformação de estratégias individuais de fuga numa estratégia coletiva que, em função das circunstâncias e do contexto, permitiu aos antigos escravos se protegerem coletiva e individualmente contra os riscos de denúncia ao se constituírem em comunidades e resistirem contra as pressões oriundas do exterior, de maneira a garantir a sua autossubsistência e, ao mesmo tempo, a desenvolver uma vida social específica, partilhando um destino comum.

Analisando a fuga dos escravos no contexto do sistema escravagista da Ilha do Marajó, Flávio Gomes precisa que o ato de fugir não deve ser entedido "como uma atitude política na qual os fugitivos contribuem como 'sujeitos de sua própria história'” (Gomes, 2005: 30). De fato, "os aspetos históricos da protestação negra são complexos e multifacetados" (ibidem: 26), em particular porque o ato de fuga e a revolta aberta e organizada são "as únicas e inexoráveis formas de protesto do negro" (ibidem: 32 ). As numerosas fugas resultantes de estratégias individuais estiveram na origem de encontros entre fugitivos de todas as categorias, que seriam levados a desenvolver entre si e com as populações indígenas locais relações particulares e a constituir por toda a parte comunidades de destino ao sabor dos eventos e das trajetórias: "indígenas, negros e desertores forjaram, nos Mocambos e Quilombos, lições de solidariedade e de aliança, inclusive com outros 
segmentos sociais diferentes dos seus" (ibidem: 232). Disso resulta a heterogeneidade social das assim chamadas comunidades de "descendentes de Quilombolas”, a qual contribui para explicar a ambiguidade da sua classificação como "Quilombolas" quando, mais tarde, num outro contexto social e político, essa denominação será retida para facilitar um tratamento social e político da situação daqueles que poderão se valer do fato de serem "os descendentes das comunidades quilombolas".

Por meio de uma categoria social comum, essa classificação intervém, com efeito, num contexto marcado pela permanência de um sistema de dominação assim apresentado por Flávio Gomes:

as lutas e a resistência contra um sistema escravagista continuam ainda hoje sob diversas formas como, por exemplo, quando as comunidades localizadas na região de Salvaterra se autodefinem como descendentes de quilombolas; elas são descendentes das gerações que lutaram de diversas maneiras para garantir os seus direitos à terra e à liberdade. (Gomes, 2005: 24)

\subsection{Os contratempos institucionais e acadêmicos da autodefinição}

Como já evocamos na introdução, a categoria de Quilombola não é evidente e a sua adoção pela Constituição de 1988, como remanescentes das comunidades de quilombos, permitiu a realização de debates no interior do meio acadêmico e entre o meio acadêmico e os especialistas da esfera administrativa (Marques e Gomes, 2013: 141-144), resultando no Decreto Presidencial 4.887/2003 instituído no primeiro governo de Luís Inácio Lula da Silva. Desses debates, nós gostaríamos de sublinhar certos argumentos que permitem compreender a complexidade e a dificuldade do ato de autodefinição exigido pelo legislador. Num artigo sobre os problemas e as contradições das políticas de desenvolvimento sustentável na Amazônia, Philippe Léna evoca as dificuldades encontradas pela administração brasileira para qualificar as populações rurais da Amazônia e, assim, explica porque "as categorias propostas são sempre ambíguas, misturando as categorias nativas, sociológicas e políticas" (Léna, 2002: 18). ${ }^{10}$ Ele sublinha em que medida essas ambiguidades contribuem para tornar imprecisas as políticas implantadas, sejam elas destinadas a populações "tradicionais", populações "indígenas" ou populações "quilombolas". Segundo Philippe Léna, essas ambiguidades resultam do fato de que essas categorias são definidas em função de particularismos que, sempre problemáticos, contribuem para "uma identidade

${ }_{10}$ Um ponto de vista compartilhado por muitos cientistas brasileiros, em meio aos quais Alfredo Wagner Berno de Almeida, Juliana Santilli, Eduardo Marques, Lilian Gomes e outros. 
construtiva"; esses particularismos nada têm de sociológicos, mas se referem a categorias "nativas". O fato de que os poderes públicos se reapropriem dessas denominações para definir os beneficiários de suas políticas faz com que "os particularismos sejam transformados em categorias políticas", impondo ao mesmo tempo às populações concernidas, que são populações dominadas, a ideia de que "não há outro caminho para obter o reconhecimento dos seus direitos universais senão conquistar o reconhecimento de seus particularismos" (ibidem: 19). Há aí algo de paradoxal (que é um dos primeiros obstáculos encontrados pelo Quilombola) em ser convidado a se reconhecer como tal e em dever, com isso, assumir um particularismo - a sua condição de negritude -, que ele frequentemente procurou apagar, usando diferentes estratégias no contexto de uma sociedade estigmatizadora. A questão nesse debate não é outra que a de "construir uma identidade negra positiva em uma sociedade que, historicamente, ensina aos negros, desde muito cedo, que para ser aceito é preciso negar-se a si mesmo [...] Uma identidade como uma construção social, histórica, cultural e plural" (Gomes, 2005: 43).

Véronique Boyer retoma a seu modo essa análise ao se interrogar sobre as razões que conduzem os antropólogos a finalmente aderirem a uma categoria administrativa que eles admitem que não é pertinente. Para ela, é claro que a única explicação plausível é a vontade desses últimos em contribuir para a resolução dos problemas encontrados pelos Quilombolas.

O interesse da sua manutenção é, portanto, antes de tudo político [...] Em outros termos, as discussões apaixonadas sobre a temática quilombola devem ser apreendidas no contexto de uma disputa visando tornar incontestável a sua existência na cena política. (Boyer, 2010: 716-717)

Véronique Boyer nos remete, assim, a uma explicação política da adesão dos cientistas às práticas que vão, em parte, contra os seus conhecimentos. Parcialmente consentida por parte do meio acadêmico das ciências sociais, essa adesão se justifica em razão das particularidades da ação pública caracterizada por uma dupla dimensão empírica e política, "de modo que as duas dimensões são praticamente inseparáveis” (Sant'Ana Júnior e Miranda, 2013: 113). Essa adesão possui como único fundamento a sua vontade de "tornar incontestável a existência dos Quilombolas sobre a cena política" e permitir que essas minorias obtenham "o reconhecimento político de que elas têm necessidade para conquistar o direito à terra" (Lima, 2002: 18).

Essa maneira de apreender o contexto institucional e político permite compreender a importância dos debates que, em Salvaterra, acompanharam 
o trabalho de autodefinição das comunidades quilombolas durante todo esse período subsequente à promulgação da Constituição. Ela permite, em particular, compreender a procrastinação de muitos deles para apreciarem as vantagens e os incovenientes desse autoreconhecimento e a busca de apoio junto a pesquisadores dotados de legitimidade na matéria, antes de se engajarem a título pessoal no interior de cada uma das suas comunidades, se autodefinirem e, assim, darem a sua contribuição pessoal para a mobilização geral das comunidades. Isso é tanto mais compreensível que "a autodenominação não leva ao reconhecimento imediato de suas demandas, de modo que as suas revindicações ainda são submetidas a intensas discussões políticas e judiciais" (Sant'Ana Júnior e Miranda, 2013: 118).

De um lado, esses debates em Salvaterra se valeram da vontade dos membros das comunidades em fazer valer no espírito da Constituição o reconhecimento de seus direitos à terra, com o objetivo de reparar uma injustiça social ligada à história dos membros dessas comunidades. Essa injustiça tendeu a se perenizar desde a criação da República sob a forma de um isolamento geográfico de suas comunidades, confinadas a uma situação de dependência política e social. De outro, esses debates foram a ocasião para muitos Quilombolas exprimirem o medo que esse reconhecimento, necessário à busca de uma solução ao seu problema, constitua ao mesmo tempo uma forma de legitimação de seu estado de dependência numa sociedade estimatizadora.

Para apreciar essa ambivalência de comportamentos a respeito do ato de autodefinição, é importante situá-los no contexto da criação das associações de Quilombolas para a defesa de seus novos direitos e da mobilização permitida por essa criação sob a forma de um processo de autoconstituição.

\subsection{Uma mobilização comunitária num contexto incerto}

Como aconteceu em praticamente todos os territórios ocupados pelos Quilombolas, em Salvaterra as suas comunidades conheceram uma grande efervescência a partir de 1989. Essa efervescência se manifestou na criação de associações em cada uma dessas 16 comunidades para defender coletivamente os seus novos direitos. Essas comunidades se beneficiaram particularmente do apoio de autoridades exteriores ao território que vieram acompanhar a mobilização local, como foi o caso da antropóloga Rosa Acevedo Marin, professora da Universidade Federal do Pará, em Belém. Fortemente implicada na organização do movimento "negro" no Brasil, Marin produziu estudos sobre as comunidades e sobre as suas reivindicações identitárias para alimentar os debates locais sobre a legitimidade dos seus membros em se reconhecerem como Quilombolas. 
Do exterior, também vieram apoios de instituições regionais da Igreja católica; foi precisamente esse o caso dos programas de formação de líderes do movimento negro iniciado nos anos 80 pela organização de encontros em Belém e pela Comissão Nacional dos Bispos do Brasil (CNBB) com o objetivo de facilitar a organização desse movimento. Nos referimos aqui aos apoios exteriores ao território, pois a paróquia católica de Salvaterra não foi implicada nesse trabalho de apoio.

A organização dessas formações de lideranças desempenhou um papel significativo na criação de uma instituição para defesa da negritude em 2004, nomeada Malungu - Coordenação Estadual das Comunidades Quilombolas do Estado do Pará. A criação dessa instituição se beneficiou do apoio de algumas entidades da Igreja Católica (em particular da FASE - Federação de Órgãos de Assistência Social e Educacional) e de uma rede internacional não governamental, com o objetivo de defender o princípio de igualdade de todos os cidadãos em suas diferenças, justificado pela história das populações negras, pela escravidão e pela sua origem africana. As referências políticas desse movimento são as da esquerda marxista, que explica a escravidão e a perenização como uma das consequências de uma sociedade de classes. Esse movimento se volta para a denúncia do "mito" de um Brasil que praticaria uma "democracia racial" e milita em favor de um reconhecimento dos ritos e práticas africanas, como a capoeira, o samba, as religiões de matriz africana e, sobretudo, o candomblé.

Em Salvaterra, um dos objetivos concretos do movimento foi encorajar e ajudar os membros das comunidades a usarem o seu direito de autodefinição. Esse trabalho de apoio foi realizado por Luzia Betânia Alcântara (Beth), que se impôs como a líder do movimento quilombola em Salvaterra. Militante e antiga catecista na Igreja Católica, Beth se beneficiou no fim dos anos 80 da formação organizada durante dois anos pela CNBB em Belém. Isso lhe permitiu estender a rede de militantes cristãos oriundos de outros horizontes e se implicar com eles na criação do movimento "negro" Malungu (depois dos primeiros encontros entre mulheres negras ocorridos em Salvaterra, na comunidade de Bacabal, em Brasília e, por fim, em Mosqueiro, distrito de Belém, a capital do Pará). ${ }^{11}$

A postura política dessa militante encarna à sua maneira a ambiguidade resultante do ato de autodefinição, na medida em que ela nasceu numa comunidade quilombola de um pai que se diz quilombo, negro e orgulhoso

${ }^{11}$ Horácio Sant'Ana Júnior e Ana Caroline Pires Miranda evocam, nestes termos, a importância desse trabalho de formação que é, ao mesmo tempo, um trabalho de certificação (Sant'Ana Júnior e Miranda, 2013: 112). 
disso: "Jovem, eu me identifiquei a um homem negro encontrado em um livro de escola, que me deixou orgulhosa de ser negra; desde então, eu me fiz respeitar como mulher negra, ainda mais porque o meu temperamento é muito forte". Ela fez essa escolha de não se autodefinir como Quilombola, assumindo o papel de líder do movimento. Esse papel é manifestamente reconhecido por todos como consequência de engajamentos sucessivos na criação de Malungu.

Beth reconhece que, depois dos seus engajamentos em Belém, foi difícil o seu retorno a Salvaterra, em particular devido a suas relações com a Igreja Católica local, que se opôs publicamente à sua ação em favor das comunidades quilombolas; aliás, foi por ocasião de seu retorno que o padre de Salvaterra ameaçou criar uma associação de cristãos brancos, para contrabalançar as ações militantes de Beth no interior da Igreja em favor dos Quilombolas. Por outro lado, ela apreciou o acolhimento que lhe reservaram as quatro comunidades nas quais ela tivera a oportunidade de partilhar a sua vida durante os anos precedentes, antes da sua instalação na cidade de Salvaterra. Desde o seu retorno, a sua principal atividade consistiu em convencer os membros das comunidades a se reconhecerem como Quilombolas; uma intervenção que se mostrou bastante necessária, uma vez que diversos membros dessas comunidades manifestavam profundas resistências em se autodefinir. Resistências que se explicam pelos preconceitos ligados à imagem inferiorizadora que a sociedade ${ }^{12}$ produz dos "negros", referindo o tradicionalismo da sua cultura, o fetichismo das suas práticas religiosas, a sua incapacidade para se organizar coletivamente e merecer vantagens. ${ }^{13}$ Nesse contexto, sua intervenção consistiu em engajar um trabalho com os membros das comunidades sobre o olhar do outro e em desconstruir a relação de dominação e de dependência para fazer disso um dos elementos centrais da sua mobilização. ${ }^{14}$

Esse apoio individual para a autodefinição foi acompanhado de um apoio coletivo para a criação de associações comunitárias habilitadas a negociar

\footnotetext{
${ }^{12}$ Percebe-se aqui de maneira precisa um dos efeitos da permanência de um sistema de dominação através da interiorização da dependência.

${ }^{13}$ De certa maneira, reconhecer-se como negro é assumir a história e a causa disso, no contexto geral da sociedade brasileira, na qual os comportamentos racistas são tão presentes, quanto em qualquer outro lugar do mundo, apesar de vários séculos de mestiçagem.

${ }^{14}$ Depois de ter esboçado o retrato do colonizado e analisado as razões de ser das representações e dos julgamentos que os colonizadores formulam sobre os colonizados, Albert Memmi chega à afirmação de que, de modo unânime e global, os julgamentos não possuem qualquer fundamento sociológico e histórico e de que as afirmações de que os colonizados são preguiçosos, ladrões, mentirosos, débeis, inaptos ao progresso, etc. nada tem de objetivo. Essa maneira de pensar representa para ele uma forma de instituição, no sentido de que, "pela sua acusação, o colonizador institui o colonizado como ser preguiçoso [...] Isso dito, torna-se evidente que o colonizado, seja qual for a função que ele assume, será sempre preguiçoso” (Memmi, 1985: 101).
} 
com o INCRA o trabalho "de delimitação, de demarcação e de certificação das terras ocupadas pelos descendentes das comunidades quilombolas" (Brasil, 2003: art. 4. ${ }^{\circ}$. Esse trabalho ${ }^{15}$ permitiu voltar atrás na história da implantação das comunidades e na história das relações que essas comunidades e os seus membros estabeleceram com a sua vizinhança, de maneira a identificar os acordos realizados entre as comunidades e os seus vizinhos, que, em geral, são fazendeiros.

A criação dessas associações e os muitos intercâmbios permitidos por ela levaram a enriquecer especificamente o objeto de reivindicações das comunidades, não se limitando apenas às reivindicações codificadas pela legislação. Foi assim que, pouco a pouco, impôs-se a ideia de reivindicações que se justificariam pela exigência de reparar uma dívida não apenas sob a forma de "um direito à terra, mas também de um reconhecimento da identidade quilombola" (entrevista de Beth). Essa reparação deveria necessariamente levar em conta a denúncia a priori estigmatizante, segundo a qual o negro não mereceria a terra, de maneira a elidir os traços que essa dívida deixou sob a forma de representações e de interiorizações da situação negra.

Disso resultaram efeitos como o fortalecimento da solidariedade dentro de cada comunidade, e entre as mesmas, pelo trabalho coletivo em espaços privados de cultivo agrícola, e pela valorização das manifestações culturais e das práticas religiosas, inclusive as de origem africana. Grande número dos nossos interlocutores evocou a esse respeito o engajamento (mais importante do que no passado) das comunidades na organização das festas de padroeiro.

Entre as oposições e as resistências que essa mobilização encontrou, os interlocutores evocaram a oposição da Igreja Católica local a certas práticas dos Quilombolas, evidenciando a influência da questão religiosa nessa mobilização em um contexto de concorrência entre igrejas. Observemos isso mais de perto.

\section{A mobilização social, entre conflitos religiosos e conflitos públicos}

A defesa da causa negra presente na mobilização das comunidades quilombolas pela reivindicação de seus novos direitos voltou-se contra a hostilidade da paróquia católica em Salvaterra, cujo padre não apenas recusou apoiar

\footnotetext{
${ }^{15}$ Esse trabalho é a ocasião de aprendizados coletivos importantes por parte de líderes das comunidades e dos agentes da instituição pública, na medida em que a abordagem engajada prevê a participação efetiva das comunidades e/ou dos seus líderes em todas as fases do processo (Brasil, 2003: art. . $^{\circ}$ ). Ele se alimenta dos relatórios redigidos por especialistas (historiadores, antropólogos, economistas, geólogos, biólogos, etc.), com o objetivo de dispor de dados confiáveis, que justificam e legitimam os avanços e as negociações em curso, de maneira a garantir "a preservação da identidade cultural dos descendentes das comunidades quilombolas".
} 
o movimento, mas também denunciou o seu caráter partidário. Ao mesmo tempo, há que ter em conta que a defesa da causa negra se beneficia do apoio de instituições da Igreja Católica brasileira de forte legitimidade como, por exemplo, a CNBB. A hostilidade da paróquia de Salvaterra manifestou-se especificamente por meio da proibição feita a Beth de perseguir as suas atividades de catequista. $\mathrm{Na}$ entrevista que ele nos concedeu, o padre da paróquia confirmou a sua vontade de se distinguir dos debates específicos às comunidades quilombolas, que deveriam se desenrolar no interior das associações comunitárias e não interferir nos debates e nas práticas de caráter religioso, que não podiam de modo algum ser específicos aos Quilombolas. No fim da estrevista, ele permaneceu por algum tempo hesitante, antes de reconhecer: "Talvez a nossa ausência de implicação enquanto Igreja nas questões quilombolas seja uma carência da Igreja?”.

Essa postura rígida da Igreja Católica se impôs face às comunidades quilombolas, que encontraram na referência a essa Igreja os símbolos, os valores e os ritos que contribuíram para forjar a sua coesão. É especificamente esse o caso de todas as festas locais, que são todas festas patronais, em referência à Igreja Católica. Postura esta a se destacar pois foi imposta em um contexto de desenvolvimento das igrejas protestantes em Salvaterra, onde um Prefeito protestante exerceu uma forte influência ao financiar a construção de 70 templos com o dinheiro público, parte destes construídos no interior de comunidades quilombolas. ${ }^{16}$ Mesmo reconhecendo que, segundo diversos dos nossos interlocutores, essa influência da concorrência entre as Igrejas teve apenas efeitos secundários sobre a mobilização das comunidades, parece-nos que, sem ser decisiva, ela alimentou as incertezas, as dúvidas e as hesitações que prolongaram os efeitos originados pelo ato de autodefinição; e é a esse título que nos parece interessante abordar e tratar dessa influência da concorrência entre as Igrejas.

Num artigo sobre a situação das comunidades quilombolas do rio Trombetas, onde, depois de ter testemunhado a mobilização dessas comunidades e a maneira pela qual, desde os anos $1989,{ }^{17}$ foram criadas numerosas associações comunitárias e reatualizados eventos de caráter frequentemente religioso, Véronique Boyer mostra como essa mobilização se beneficiou, num primeiro momento, de um importante apoio da Igreja Católica, que facilitou a organização de comunidades, engajando-se especificamente na

\footnotetext{
${ }_{16}$ Atualmente, $80 \%$ dos Quilombolas são católicos e apenas dois dos 15 presidentes de associações são protestantes.

${ }^{17}$ Essa mobilização rapidamente adquiriu importância. Somente no Estado do Pará, 229 comunidades quilombolas foram identificadas até 1998 , apenas 10 anos depois da promulgação da nova Constituição.
} 
formação dos seus líderes. O artigo revela em seguida a maneira pela qual a concorrência entre as igrejas católicas e as protestantes interferiram nessa mobilização:

Pode-se razoalvemente supor que, quando a legitimidade da luta pela terra se afirma pela participação em festas católicas, uma coletividade se sente ameaçada pela presença, mesmo minoritária, de outro grupo religioso, e pelo interesse que esse suscita junto aos de fora. (Boyer, 2003: 31)

Num contexto no qual as revelações dos Quilombolas se manifestam especificamente por ocasião das festas e dos rituais religiosos, Véronique Boyer procurou examinar em que medida a escolha por parte de certos elementos desta comunidade de deixar a Igreja católica e de aderir à Igreja protestante (a escolha da dissidência em relação a um engajamento religioso anterior) poderia ter efeitos sobre a mobilização coletiva dessas mesmas comunidades, mobilização essa que o trabalho da Igreja católica auxiliou. Essa dissidência se explica menos por motivos religiosos do que pela necessidade de parte dos membros dissidentes tornarem visíveis as divergências existentes entre os membros dessas comunidades, como ela constata: "A adesão à crença parece um meio de se substrair às hierarquias sociais locais para recompor redes de relações onde cada um espera ver a sua posição melhorar" (ibidem: 32 ).

Sem negar o peso da estrutura autoritária das Igrejas evangélicas, me parece que o motivo religioso (conhecimento da Bíblia, a transformação, etc.) vem aqui mais apoiar uma dissidência de fato, do que a provocar. $\mathrm{O}$ argumento da submissão à autoridade religiosa constitui antes de tudo uma justificativa, fácil e inteligível por todos, da sua posição de retraimento. (ibidem)

Para justificar essa interpretação, a autora sublinha a maneira pela qual esses Quilombolas “dissidentes” assumem as contradições entre a rejeição por parte da Igreja Evangélica a todo engajamento público de seus integrantes em nome da religião ("qualquer iniciativa política, qualquer tentativa da organização da coletividade é considerada como obra do diabo") e a vontade deles em continuar a se afirmar como Quilombolas. Assim, exprimem as suas divergências "em relação a uma ação política que toma emprestado de outra religião (o catolicismo) os elementos necessários para construir a sua legitimidade"(Boyer, 2003: 33), utilizando argumentos religiosos católicos para definir a "negritude" de descendentes de Quilombolas. 
Essas dissidências religiosas aparecem como estratégias individuais de denúncia de divergências no interior da mobilização. A esse respeito, elas são significativas não de divergências teológicas e ideológicas, mas de novas relações de força que o movimento social deve assumir para se desenvolver. Elas resultam especificamente das dificuldades que a mobilização encontra na sua pesquisa de apoios externos, apoios esses que não se limitam ao apoio das Igrejas, mas que concernem igualmente certos especialistas e cientistas, certas organizações não governamentais ou, ainda, os movimentos sociais que possuem relação com a causa negra (como é o caso da Malungu) ou com a luta contra as discriminações sociais e raciais.

Os políticos são geralmente muito eficazes em se imiscuir nos jogos de alianças, com o único objetivo de tirar vantagem das dissidências que sempre se manifestam nessas ocasiões, como foi o caso do Prefeito de Salvaterra depois da eleição de 2004, referida anteriormente. Para compreender em que medida a sua intervenção contribuiu para ampliar os efeitos das dissidências e para multiplicar os riscos da mobilização social das comunidades, é importante mencionar que esse Prefeito começou por surpreender os membros das comunidades ao aderir ao partido da direita liberal algumas semanas depois da sua eleição. Essa reviravolta foi tanto mais incompreensível pelas comunidades que ela foi acompanhada de tomadas de posição públicas nas quais ele afirmava que jamais aceitara os negros e que sempre disse desconhecer o que era quilombola, mesmo se ele negociou e obteve o seu apoio antes de se engajar na campanha. Aliás, o seu engajamento em favor da Igreja Evangélica não se limitou à construção de templos; ele também se manifestou através da denúncia das práticas culturais dos Quilombolas, ao rescindir o contrato de trabalho de uma professora de escola que organizara uma festa na qual foram realizados ritos africanos em contexto escolar. Essa postura da parte do Prefeito confirma o poder que ele exerce sobre os cidadãos não apenas a título pessoal, mas também em função do seu cargo no inte-rior do sistema de dominação tratado no início deste artigo.

No mesmo tempo, essa estratégia de manipulação do Prefeito encontrou resistências por parte das comunidades que limitaram o impacto sobre a sua mobilização; foi esse especificamente o caso de uma presidente de associação, que afirmou "eu sou negra e tenho orgulho disso; aliás, tenho muito orgulho disso!”, e que compreendeu que o que aconteceu naquela ocasião foi um descrédito suplementar da classe política. É provável que não tenha sido a única a reagir dessa maneira e que a provocação do Prefeito tenha produzido, por um lado, resistências que contribuem para aumentar a mobilização e, por outro, o efeito contrário, influenciando nas divisões de 
caráter religioso entre os membros das comunidades e ampliando os riscos enfrentados pela sua mobilização.

Assim, parece que, se os conflitos enfrentados pelos Quilombolas para defender os seus direitos tanto do lado religioso quanto do lado político levaram à amplificação dos riscos da mobilização, esses mesmos conflitos estiveram na origem de atos de resistência e de estratégias de oposição; deram inclusivamente origem a aprendizados coletivos que permitiram aos membros das comunidades acederem a um melhor conhecimento e domínio dos seus direitos. A esse respeito muito se falou de consenso, quanto ao trabalho de demarcação de terras engajado com os técnicos do INCRA. A prova disso é que as reivindicações avançadas por essa mobilização vão muito além desse trabalho de demarcação; elas concernem especificamente à afirmação da identidade quilombola.

A tomada de consciência da importância assumida pela identidade nesse contexto levou nomeadamente a incitar os líderes das comunidades a exigirem um ensino adaptado à origem da escravidão e à sorte reservada às populações negras na história do Brasil, de maneira a despertar a curiosidade e a esclarecer a sua consciência. É para esse fim que, com o apoio da nova equipe municipal, mais aberta à questão quilombola, foram recentemente propostos ateliês de formação em música e o ensino da história da escravidão no Brasil.

\section{Considerações finais sobre as condições da mobilização}

No contexto de Salvaterra, o reconhecimento das comunidades quilombolas está associado a uma mobilização a partir da autodefinição até à demarcação das terras pelos representantes do Estado federal, um processo que integra o trabalho de organização das comunidades e que conta em boa medida com o "potencial de mobilização". Essa mobilização se concretiza pelas reivindicações que vão muito além do que prevê o quadro oferecido pela Constituição: trata-se do reconhecimento de tudo o que se refere às práticas, aos valores, aos rituais e a todo tipo de manifestação por meio da qual as comunidades e os seus membros exprimem a sua identidade. Tal mobilização baseia-se na afirmação de uma "cultura diferenciada" (Santilli, 2005: 85) em uma sociedade pluriétnica e pluricultural. ${ }^{18}$

Assim, em um contexto muito diferente, o da Ilha de Marambaia no sul do Rio de Janeiro, onde as comunidades quilombolas tiveram que

\footnotetext{
${ }_{18}$ Sob a perspectiva socioambiental, Juliana Santilli demonstra que a Constituição de 1988 contribui para a construção de uma sociedade multicultural e pluriétnica (Santilli, 2005: 42)
} 
resistir à vontade da Marinha de Guerra de deslocá-los do território, Fábio Reis Mota mostra como elas conseguiram encontrar apoios numa rede nacional, "participando de eventos nacionais, reuniões interministeriais, falando em rádios, jornais, publicizando textos e fazendo demandas a orgãos governamentais". Resulta disso que

o quilombola foi incorporado na dinâmica local a partir de discursos e cumprimentos (saudações quilombolas), bem como nas vestimentas, nas histórias, nos livros e no dia a dia em que vivem e experimenciam esse novo regime de engajamento: ser quilombola. (Mota, 2011: 254)

No campo religioso, as reivindicações identitárias se voltam contra as concepções teológicas dos que, no interior da Igreja Católica, recusam toda forma de sincretismo em nome da "verdade" e rejeitam as proibições oriundas da maior parte das igrejas protestantes. Ao mesmo tempo, essa mobilização tira proveito do apoio essencial trazido por aqueles que se referem à teologia da libertação para encorajar essa mobilização e para denunciar as injustiças herdadas da colonização e mantidas pela permanência de um sistema de dominação.

O mesmo se verifica no campo político, onde as reivindicações identitárias se encontram regularmente questionadas pelos efeitos perversos de um sistema de dominação que impregna o conjunto das relações entre os Quilombolas e os atores do sistema de poder local.

Neste artigo procurou-se mostrar, em um contexto de afirmação de sua identidade, que a mobilização conseguiu superar contratempos resultantes das intervenções políticas, aproveitando discursos e argumentos críticos para denunciar as discriminações sociais e raciais das quais eles se consideram vítimas. A mobilização em questão age permanentemente sobre interações complexas e ocasionais entre os atos e as estratégias individuais dos membros das comunidades (por exemplo, o ato de autodefinição e as estratégias que o acompanham) e os atos e as estratégias coletivas (por exemplo, o trabalho de demarcação da terra e as modalidades da gestão coletiva dos seus usos) com o objetivo de conquistar um bem comum, o território, e de tirar proveito dos diferentes usos, tanto individuais quanto coletivos, por parte das comunidades.

Se nós nos referirmos aos dois quadros teóricos que nos permitiram organizar a apresentação de nossos resultados, parece claramente que o paradoxo de Mancur Olson (Olson, 1999) não nos permite explicar o essencial do que está em questão nessa mobilização. Certamente, o ato de autodefinição resulta de uma escolha individual, que poderia se justificar pela 
atração de um benefício pessoal. Entretanto, não é de modo algum isso que se passa, como nos revela de maneira particularmente significativa a expressão repetida por duas pessoas entrevistadas "eu sou negra e tenho orgulho disso". Incontestavelmente, "eu sou negra" remete ao ato de autodefinição; mas "tenho orgulho disso" representa tudo o que esse ato, difícil de assumir pelas diferentes razões que apresentamos e ambíguo do ponto de vista da sua significação, contém de potencial de mobilização, que vai se manifestar especificamente pela organização das comunidades e pelas numerosas manifestações culturais e simbólicas, que adquirem um sentido muito particular no contexto da afirmação identitária. Esse potencial de mobilização confirma a pertinência em considerar que essas comunidades de fato se apresentam como "unidades de mobilização" e que a dinâmica própria à organização delas e ao engajamento de seus membros no trabalho de demarcação resulta efetivamente desse "processo de autoconstrução" que tira uma parte da sua legitimidade e uma parte do seu potencial de mobilização e da sua capacidade para coproduzir ações locais de caráter público.

A existência desse processo de autoconstrução, interpretada por Alfredo Wagner de Almeida como um processo de territorialização (Almeida et al., 2010: 335), mostra que o engajamento individual e a mobilização da qual participa são resultados de um jogo permanente e complexo de interações entre estratégias individuais e coletivas, e a reinvindicação de benfeitorias a título igualmente individual e coletivo. Assim, a permanência dessa mobilização aparece como fruto da capacidade dos atores locais para responder às exigências de um projeto coletivo (o reconhecimento de seu território e da sua identidade), ao mesmo tempo em que satisfaz as expectativas individuais dos Quilombolas (o reconhecimento da sua cidadania plena e inteira).

Essa análise confirma o quadro teórico proposto por Daniel Cefaï e os seus colegas, que consideram que o "engajamento pessoal e a mobilização coletiva contribuem para a formulação da experiência do mundo, de si e do outro, e para a emergência de normas éticas, jurídicas e políticas de um bem-viver coletivo" (Cefaï et al., 2011: 51). Essa mobilização procede por uma forma de densificação das relações entre as comunidades e os seus membros, na perspectiva dos "regimes de proximidade" (em razão especificamente de laços de familiaridade com as coisas e com as pessoas), e entre as comunidades e os seus parceiros, na perspectiva dos "regimes de ação pública" (em razão do caráter público dos seus parceiros, que participam da produção dessas ações) (Mota, 2011: 255-256). Essas reivindicações tocam aspectos da vida das comunidades. Os seus efeitos são ambivalentes: ao mesmo tempo em que eles estão na origem de novos conflitos locais, eles também são a ocasião de uma melhor integração da mobilização no processo político. 
Todos esses fatores contribuiriam, segundo os nossos colegas, "para ultrapassar suas divisões e formar alianças, constituir uma força consequente em termos de visibilidade e, talvez, ganhar um reconhecimento legal e político" (Cefaï et al., 2011: 49).

Esse "reconhecimento legal" advém da demarcação do território realizado pelo Governo Federal e esse "reconhecimento político" é resultado de uma politização das reivindicações oriundas das comunidades quilombolas, testemunho de uma capacidade para denunciar não apenas as injustiças sociais por elas sofridas, mas também o próprio sistema de poder que, ao nível local, está na origem da permanência de grande parte dessas injustiças.

\section{Referências bibliográficas}

Almeida, Alfredo Wagner Berno (1996), "Quilombos: sematologia face a novas identidades”, in Projeto Vida de Negro (org.), Frechal terra de preto: quilombo reconhecido como reserva extrativista. São Luís: SMDDH/CCN, 11-19.

Almeida, Alfredo Wagner Berno (2002), "Os quilombos e as novas etnias", in Eliane Cantarino O'Dwyer (org.), Quilombos - Identidade étnica e territorialidade. Rio de Janeiro: FGV/ABA.

Almeida, Alfredo Wagner Berno de (2008a), Antropologia dos archivos da Amazônia. Rio de Janeiro: Casa 8/Fundação Universidade do Amazonas.

Almeida, Alfredo Wagner Berno de (2008b), Terra de quilombo, terras indígenas, "babaçuais livres", "castanhais do povo", faxinais e fundo de pasto: terras tradicionalmente ocupadas. Manaus: PGSCA-UFAM - Programa de Pós-Graduação em Sociedade e Cultura da Amazônia da Universidade Federal do Amazonas [2. ${ }^{a}$ ed.].

Almeida, Alfredo Wagner Berno de; Marin, Rosa Elizabeth Acevedo; Cid, Ricardo; Müller, Cíntia Beatriz; Farias Júnior, Emmanuel de Almeida (orgs.) (2010), Projeto nova cartografia social da Amazônia. Manaus: UEA Edições.

Boyer, Véronique (2003), "A etnicidade dos quilombolas e a religião dos evangelhos: um exemplo do baixo Amazonas”, Boletim Rede Amazônia, 2(1), 29-36.

Boyer, Véronique (2010), "Une forme d'africanisation au Brésil. Les quilombolas entre recherche anthropologique et expertise politico-légale”, Cahiers d'études africaines, 198-199-200, 707-730.

Brasil, Constituição (1988), Constituição da República Federativa do Brasil. Brasília, DF: Senado.

Brasil (2003), "Decreto n. ${ }^{\circ} 4.887$, de 20 de novembro de 2003, Regulamenta o procedimento para identificação, reconhecimento, delimitação, demarcação e titulação das terras ocupadas por remanescentes das comunidades dos quilombos de que trata o art. 68 do Ato das Disposições Constitucionais Transitórias". Consultado a 22.03.2018, em https://www.planalto.gov.br/ccivil_03/decreto/2003/D4887.htm. 
Castro, Edna Maria Ramos de (1997), “Território, biodiversidade e saberes de populações tradicionais”, in Edna Maria Ramos de Castro; Florence Pinton (orgs.), Faces do trópico úmido. Conceitos e questões sobre desenvolvimento e meio ambiente. Pará/São Paulo: Editora Cejup/UFPA-NAEA - Núcleo de Altos Estudos Amazônicos da Universidade Federal do Pará, 221-242.

Castro, Edna Maria Ramos de (2000), “Território, biodiversidade e saberes de populações tradicionais”, in Antonio Carlos Diegues (org.), Etnoconservação: novos rumos para a proteçao da natureza nos trópicos. São Paulo: HUCITEC Editora/NUPAUBUSP - Núcleo de Apoio à Pesquisa sobre Populações Humanas e Áreas Úmidas da Universidade de São Paulo, 165-182 [2. ${ }^{\text {a }}$ ed.].

Cefaï, Daniel; Mello, Marco Antonio da Silva; Mota, Fábio Reis; Veiga, Felipe Berocan (orgs.) (2011), Arenas públicas: por uma etnografia da vida associativa. Niterói: Editora da Universidade Federal Fluminense.

CONAQ - Coordenação Nacional de Articulação das Comunidades Negras Rurais Quilombolas (2010), “Manifesto pelos Direitos Quilombolas”, in Alfredo Wagner Berno de Almeida; Rosa Elizabeth Acevedo Marin; Ricardo Cid; Cíntia Beatriz Müller; Emmanuel de Almeida Farias Júnior (orgs.), Projeto Nova Cartografia Social da Amazônia. Manaus: UEA Edições, 268-290.

Gomes, Flavio dos Santos (2005), A bidra e os pântanos: quilombos e comunidades de fugitivos no Brasil (séculos XVII-XIX). São Paulo: Editora da Universidade Estadual Paulista.

Gomes, Lilian Cristina Bernardo (2009), "Justiça seja feita: direito quilombola ao território”. Tese de doutorado apresentada ao Programa de Pós-Graduação em Ciência Política, Belo Horizonte, Faculdade de Filosofia e Ciências Humanas da Universidade Federal de Minas Gerais, Brasil.

IBGE - Instituto Brasileiro de Geografia e Estatística (2010), Censo demográfico. Rio de Janeiro: Editora IBGE.

Léna, Philippe (2002), "As políticas de desenvolvimento sustentável para a Amazônia - Problemas e contradições”, Boletim Rede Amazônia, 1(1), 9-22.

Lima, Déborah de Magalhães (2002), "Ethique et politique environnementale en Amazonie contemporaine", Lusotopie, 1, 13-23.

Marques, Carlos Eduardo; Gomes, Lilian (2013), "A Constituição de 1988 e a ressignificação dos quilombos contemporâneos. Limites e potencialidades”, Revista Brasileira de Ciências Sociais, 28(81), 137-153.

Memmi, Albert (1985), Portrait du colonisé. Portrait du colonisateur. Paris: Gallimard. Mota, Fabio Reis (2011), "Quanto custa ser quilombola no Brasil? Mobilizações coletivas e associativismo no Brasil contemporâneo”, in Daniel Cefaï; Marco Antonio da Silva Mello; Fábio Reis Mota; Felipe Berocan Veiga (orgs.), Arenas públicas: por uma etnografia da vida associativa. Niterói: Editora da Universidade Federal Fluminense, 239-262. 
Olson, Mancur (1999), Lógica da ação coletiva. São Paulo: Editora da Universidade de São Paulo.

Santilli, Juliana (2005), Socioambientalismos e novos direitos - Proteção jurídica à diversidade biológica e cultural. São Paulo: Peirópolis.

Sant'Ana Júnior, Horácio Antunes de; Miranda, Ana Caroline Pires (2013), “Conflitos ambientais na Amazônia e a construção de catagorias sociológicas e jurídicas: análise da expressão 'povos e comunidades tradicionais'”, Revista Pós Ciências Sociais, 10(20), jul./dez., 103-120.

Teisserenc, Pierre (2016a), "Poder local e condições de sua renovação na Amazônia", Novos Cadernos Naea, 19(1), 47-70.

Teisserenc, Pierre (2016b), “As vias de integração da mobilização social no campo político”, Caderno CRH, 29(77), 243-259.

Artigo recebido a 31.05.2016

Aprovado para publicação a 19.12.2017

\section{Pierre Teisserenc}

Universidade Federal do Pará

Avenida Augusto Correa, 01, 66075-110, Guamá, Belém, Pará, Brasil

Contacto: pierre-teisserenc@wanadoo.fr

\section{Maria José da Silva Aquino Teisserenc}

Universidade Federal do Pará

Avenida Augusto Correa, 01, 66075-110, Guamá, Belém, Pará, Brasil

Contacto: mjaq@uol.com.br

\section{Mobilization, Conflicts and Recognition of the Territory: Quilombolas Communities in the Marajó Island, Brazil}

This article discusses the implementation of a mechanism from the 1988 Brazilian Constitution to repair the situation of historical injustice experienced by the Quilombola communities of Salvaterra, Marajó Island, as an opportunity for a mobilization of identity to claim recognition of social rights. As the local power

\section{Mobilisation, conflits et reconnais- sance du territoire: communautés quilombolas dans l'île do Marajó, Brésil}

Dans cet article nous nous penchons sur la mise en place d'un dispositif de la Constitution Brésilienne de 1988 visant à réparer une situation d'injustice vécue par les communautés quilombolas de Salvaterra, Île de Marajó, en tant qu'opportunité d'une mobilisation au caractère identitaire pour revendiquer la reconnaissance 
does not commit itself to this implementation, but at the same time is called upon to take concrete measures in the territory, tensions and conflicts in the political and religious spheres are then manifested. The Quilombolas' strategies vis-à-vis local, religious and political authorities for differentiated recognition contribute to a politicization of local challenges although the constitutional mechanism does not provide the means for mobilization to call into question a system of traditional domination on which the local power is based. Keywords: identity; Quilombola communities; mobilization; politicization; sociology of conflicts; territoriality. de droits sociaux. Comme le pouvoir local ne s'engage pas au niveau de cette mise en œuvre mais, qu'en même temps, il est interpellé afin de prendre des mesures concrètes sur le territoire, il en découle des tensions et des conflits manifestes dans les sphères politique et religieuse. Les stratégies des Quilombolas face aux autorités locales, religieuses et politiques, visant la reconnaissance différenciée, contribuent à une politisation des défis locaux, bien que le dispositif constitutionnel mis en action n'offre pas les moyens nécessaires à ce que la mobilisation remette en cause un système de domination traditionnelle sur lequel repose le pouvoir local.

Mots-clés: communautés quilombolas; identité; mobilisation; politisation; sociologie des conflits; territorialité. 